\title{
Substituição total do milho por sorgo e óleo de abatedouro avícola em dietas para frangos de corte
}

\author{
Vitória Régia Ramos de Albuquerque Rocha ${ }^{1}$, Wilson Moreira Dutra Júnior ${ }^{2}$, Carlos Bôa- \\ Viagem Rabello ${ }^{2}$, Ricardo Pimentel Ramalho ${ }^{3}$, Maria do Carmo Mohaupt Marques Ludke ${ }^{2}$, \\ Elisabete Cristina da Silva ${ }^{4}$
}

\author{
1 PDIZ - UFPB/UFRPE/UFC. \\ ${ }^{2}$ Departamento de Zootecnia/UFRPE. \\ ${ }^{3}$ CCBS/ FEJAL - CESMAC. \\ ${ }^{4}$ Curso de Graduação em Zootecnia - UFRPE.
}

RESUMO - Com o objetivo de avaliar o efeito da substituição total do milho por sorgo e níveis crescentes de óleo de abatedouro avícola (OAA) sobre os parâmetros de desempenho, as características e o rendimento de carcaça de frangos de corte, foram utilizados 260 pintos de 1 dia, machos, da linhagem Cobb, submetidos aos seguintes tratamentos: uma ração-referência à base de milho e quatro rações à base de sorgo com inclusões de 0; 2,5; 5 e 7,5\% de OAA de acordo com as fases de criação ( 1 a 7 dias, 8 a 21 dias, 22 a 33 dias e 34 a 42 dias). O delineamento experimental foi em blocos casualizados, com dois blocos formados conforme o sentido do galpão, duas repetições por bloco, 13 aves por parcela e cinco tratamentos. Não foi observado efeito de bloco sobre as variáveis analisadas entre os tratamentos. A inclusão de OAA nas rações à base de sorgo teve efeito linear sobre o consumo de ração (CR), exceto durante a primeira fase, e o ganho de peso, que aumentou nas fases de 1 a 7 dias, 22 a 33 dias e 1 a 42 dias de idade. A conversão alimentar e a viabilidade não apresentaram diferenças significativas nas fases estudadas. O peso absoluto dos frangos ao abate aumentou linearmente com a adição de OAA na ração. Os pesos e rendimentos da carcaça quente, da carcaça fria, da carcaça após resfriamento de 24 horas, dos cortes nobres, das vísceras comestíveis e da gordura abdominal não foram influenciados pelas rações. A pigmentação da carcaça não foi influenciada pela inclusão de OAA em rações à base de sorgo. O sorgo pode substituir totalmente o milho a partir do $8^{\underline{o}}$ dia de idade, pois não interferiu negativamente no desempenho e no rendimento de carcaça. A adição de até 7,5\% de OAA em rações à base de sorgo possibilita a produção de carcaças com rendimentos semelhantes ao daquelas obtidas com o fornecimento de rações à base de milho e de farelo de soja, no entanto, é necessária a adição de pigmentos.

Palavras-chave: alimentação alternativa, aves, desempenho, rendimento de carcaça, resíduo de abatedouro

\section{Total replacement of corn by sorghum and slaughterhouse poultry oil in broiler diets}

\begin{abstract}
This study was carried out to evaluate the effect of total replacement of corn by sorghum and crecent levels of slaugherhouse poultry oil (PO) on performance and carcass characteristics and yield of broilers. A total of 260 chicks one day-old, males, Cobb strain, was allotted to the following treatments: a corn based reference ration, and four sorghum based diets with the inclusion levels of $0,2.5,5$, and $7.5 \%$ of PO according to the growing phases (from 1 to 7 days, 8 to 21 days, 22 to 33 days and 34 to 42 days). The experimental desing was in radomized blocks, with two blocks, where the parameter for blocks was the sense of the hangar, two replicates per block, with 13 birds per pen and five treatments. The inclusion of PO in the sorghum based diet linearly increased feed intake (FI), except during the first phase, and showed a linear effect on weight gain, that increased in the phases from 1 to 7 days, 22 to 33 days, and 1 to 42 days. Feed conversion (FC) and viability did not showed differences in the studied phases. The absolute weight at slaughter broilers lineally increased with the addition PO in the diet. The weights and yield hot carcass, cold carcass, freezing 24 hours carcass, prime cuts, edible visceras, abdominal fat was not influenced by the diets. Carcass pigmentation did not show difference by the addition of PO in the sorghum based diet. The sorghum could totally replacement corn, from the day 8 , because did not negatively affect performance and carcass yield. The addition of up to $7.5 \%$ of PO in the sorghum based diet provide carcass production with yield similar to those fed corn soybean meal based diets, but the addition of pigments is important.
\end{abstract}

Key Words: alternative feed, birds, carcass yield, performance, slaughterhouse residue 


\section{Introdução}

O uso de alimentos alternativos na alimentação de frangos de corte é importante para redução de custos na fabricação de rações, desde que não influenciem negativamente o desempenho e a qualidade das aves. Subprodutos industriais como óleos vegetais e gorduras animais podem ser aproveitados na alimentação animal por aumentarem a densidade da ração, diminuir a inclusão de milho e de farelo de soja, melhorarem a palatabilidade e a textura da ração e, ainda, facilitarem a absorção de vitaminas lipossolúveis, de cálcio e de pigmentos. A utilização destes ingredientes é considerada a principal causa dos crescentes aumentos na produtividade e no desempenho de frangos de corte nos últimos anos (Arellano, 1992).

Entre os alimentos alternativos, o sorgo se destaca nas pesquisas por suas características nutricionais; e reqüentemente, é utilizado como fonte alternativa ao milho, principalmente nas regiões semi-áridas e tropicais, onde sua cultura apresenta melhor rendimento de nutrientes por unidade de área (Tabosa et al., 1993; Anualpec, 2000). Além disso, seu valor nutricional corresponde a $95 \%$ do milho e custa $88 \%$ do preço deste cereal, constituindo-se na mais promissora fonte de energia em substituição ao milho em rações para animais não-ruminantes.

O sorgo tem características nutritivas semelhantes às do milho; apesar de ligeiramente inferior em valor energético, é um pouco mais rico em proteína. No entanto, o milho contém mais extrato etéreo e níveis superiores de aminoácidos essenciais (Whitaker \& Carvalho, 1997). O sorgo também possui baixo teor de xantofila e caroteno, responsáveis pela pigmentação amarelo-alaranjada na pele dos frangos e na gema do ovo, característica importante na preferência do consumidor, embora sem valor nutritivo. Além disso, o sorgo apresenta menos umidade e valores similares de nutrientes (Vasconcelos, 1988; Zardo \& Lima, 1999).

Outro ingrediente alternativo utilizado em grande escala pela indústria avícola são os subprodutos de abatedouros, entre eles, o óleo de abatedouro avícola, um subproduto ou resíduo avícola proveniente do processamento industrial do frango bastante utilizado nas fábricas de rações animal e nas indústrias de produtos alimentícios e de beleza. Possui rica composição lipídica, elevado teor energético (Chiu \& Gioielli, 2001), além de baixo custo (Racanicci et al., 2002).

A comparação da gordura de frango a outras gorduras animais, como banha e sebo, comprova que a gordura de frango apresenta alta porcentagem de ácidos graxos insaturados e poliinsaturados. Em virtude do alto grau de insaturação, esta gordura é semilíquida à temperatura ambiente e seu baixo ponto de fusão está relacionado ao baixo conteúdo de ácidos graxos saturados (Chiu \& Gioielli, 2001). Esta gordura possui odores e flavores naturais desejáveis, tornando-se adequada como ingrediente de alimentos e como base gordurosa na formulação de rações.

Segundo Marusich \& Bauerfeind (1981), a adição de gorduras e óleo nas rações pode melhorar a absorção dos carotenóides presentes na dieta, entretanto, essa melhoria da coloração com a adição de gordura e óleos também pode estar relacionada à correta relação energia : proteína (Bell \& Miles, 1986).

Andreotti et al. (2000), estudando algumas fontes de gordura para frangos de corte, como óleo de frango, óleo de milho refinado, banha suína e outros, concluíram que as fontes de gorduras não proporcionaram alterações nos rendimentos de carcaça e de cortes nobres e na porcentagem de gordura abdominal que pudessem denotar a superioridade de alguma fonte sobre outra.

Nesta pesquisa, avaliou-se a utilização do sorgo e de óleo de abatedouro avícola para verificar o efeito da substituição total do milho por sorgo com o uso de óleo de abatedouro avícola em rações para frangos de corte de 1 a 42 dias, sobre o desempenho e as características e os rendimentos de carcaça.

\section{Material e Métodos}

O experimento foi conduzido nas instalações do Setor de Avicultura do Departamento de Zootecnia da Universidade Federal Rural de Pernambuco, UFRPE, durante 42 dias utilizando-se 260 pintos de corte machos da linhagem Cobb com 1 dia de idade, selecionados de acordo com o peso médio inicial (aproximadamente $43 \mathrm{~g}$ ). Os pintinhos foram alojados em um galpão de alvenaria, subdividido em 28 boxes de 1,95 × 0,87 m, distribuídos 14 boxes de cada lado.

O experimento foi conduzido em um delineamento de blocos casualizados, com cinco tratamentos, dois blocos e duas repetições por bloco. O critério para a formação dos blocos foi a localização dos boxes no galpão. Foram utilizadas 13 aves por parcela com espaçamento de $130 \mathrm{~cm}^{2}$ por ave, em um total de 20 parcelas.

Os tratamentos experimentais consistiram de: raçãoreferência à base de milho e farelo de soja; ração com substituição total do milho por sorgo sem utilização de OAA; ração com substituição total do milho por sorgo com inclusão de 2,5\% de OAA; ração com substituição total do milho por sorgo com inclusão de 5\% de OAA; e ração com substituição total do milho por sorgo com inclusão de 7,5\% de OAA. As dietas formuladas foram isoprotéicas e 
isoenergéticas, de acordo com as composições químicas e os valores energéticos dos alimentos descritos por Rostagno et al. (2000) (Tabelas 1, 2, 3 e 4 ).

O programa de alimentação adotado foi composto de quatro fases: 1 a 7 dias (pré-inicial), 8 a 21 dias (inicial), 22 a 33 dias (crescimento) e 34 a 42 dias (final) (Rostagno et al., 2000). Semanalmente, durante toda fase experimental, foram realizadas pesagens dos frangos e das sobras de ração de cada parcela, além de registros de mortalidade. Em cada fase e no período total (1 a 42 dias) foram avaliados o consumo médio de ração (CMR), o ganho médio de peso (GMP), a conversão alimentar (CA) e a viabilidade econômica da ração.

Aos 42 dias de idade, três aves de cada repetição foram selecionados de acordo com o peso médio de cada parcela

Tabela 1 - Composição das rações experimentais fornecidas na fase de 1 a 7 dias de idade (\%MN)

\begin{tabular}{|c|c|c|c|c|c|}
\hline \multirow[t]{3}{*}{ Item } & \multicolumn{5}{|c|}{ Ração (\%) } \\
\hline & \multirow[t]{2}{*}{ Referência } & \multicolumn{4}{|c|}{ Sorgo + Nível de OAA (\%) } \\
\hline & & 0,0 & 2,5 & 5,0 & 7,5 \\
\hline \multicolumn{6}{|l|}{ Ingrediente (\%) } \\
\hline Milho & 57,196 & - & - & - & - \\
\hline $\begin{array}{l}\text { Farelo de soja } \\
(45 \%)\end{array}$ & 27,672 & 19,480 & 29,552 & 37,185 & 38,684 \\
\hline $\begin{array}{l}\text { Soja integral } \\
\text { extrusada }\end{array}$ & 10,814 & 20,670 & 8,622 & - & - \\
\hline Sorgo & - & 55,437 & 54,972 & 52,528 & 45,097 \\
\hline $\begin{array}{l}\text { Óleo de abatedouro } \\
\text { avícola (OAA) }\end{array}$ & o - & - & 2,500 & 5,000 & 7,500 \\
\hline Fosfato bicálcico & 1,894 & 1,870 & 1,873 & 1,881 & 1,902 \\
\hline Calcário & 1,101 & 1,117 & 1,097 & 1,078 & 1,060 \\
\hline Sal comum & 0,470 & 0,500 & 0,478 & 0,461 & 0,460 \\
\hline $\begin{array}{l}\text { Premix } \\
\text { vitamínico- } \\
\text { mineral }^{1}\end{array}$ & 0,400 & 0,400 & 0,400 & 0,400 & 0,400 \\
\hline Inerte & - & - & - & 0,983 & 4,441 \\
\hline DL-met 99 & 0,251 & 0,279 & 0,281 & 0,283 & 0,289 \\
\hline L-Lys HCl & 0,202 & 0,246 & 0,225 & 0,201 & 0,169 \\
\hline \multicolumn{6}{|c|}{ Composição nutricional calculada } \\
\hline EM (kcal/kg) & 2.950 & 2.950 & 2.950 & 2.950 & 2.950 \\
\hline PB (\%) & 21,915 & 21,915 & 21,915 & 21,915 & 21,915 \\
\hline Met total (\%) & 0,583 & 0,601 & 0,604 & 0,606 & 0,610 \\
\hline $\begin{array}{l}\text { Met + Cys } \\
\text { totais (\%) }\end{array}$ & 0,926 & 0,926 & 0,926 & 0,926 & 0,926 \\
\hline Lisina total (\%) & 1,307 & 1,307 & 1,307 & 1,307 & 1,307 \\
\hline Trip. total (\%) & 0,268 & 0,280 & 0,285 & 0,289 & 0,292 \\
\hline P disponível (\%) & 0,466 & 0,466 & 0,466 & 0,466 & 0,466 \\
\hline Сa $(\%)$ & 0,988 & 0,988 & 0,988 & 0,988 & 0,988 \\
\hline Na $(\%)$ & 0,224 & 0,224 & 0,224 & 0,224 & 0,224 \\
\hline
\end{tabular}

${ }^{1}$ Premix vitamínico e mineral para aves (ração inicial)/kg de ração: ácido fólico - 106,00 mg, ácido pantotênico - 2.490,00 mg, antifúngico - 5.000,00 $\mathrm{mg}$, antioxidante $-200,00 \mathrm{mg}$, biotina - 21,00 mg, Cu - 2.000,00 mg, coccidiostático $-15.000,00 \mathrm{mg}$, colina $-118.750,00$, Fe $-12.500,00 \mathrm{mg}$, I - $190,00 \mathrm{mg}, \mathrm{Mn}-18.750,00 \mathrm{mg}$, menadiona - 525,20 mg, niacina $7.840,00 \mathrm{mg}$, piridoxina $-210 \mathrm{mg}$, promotor de crescimento $-7.500,00 \mathrm{mg}$, riboflavina - $1.660,00 \mathrm{mg}$, Se $-75,00 \mathrm{mg}$, tiamina - 360,00 mg, vit. A 2.090.000,00 UI, vit. B12 - 123.750,00 mcg, vit. D3 - 525.000,00 UI, vit. $\mathrm{E}-4.175,00 \mathrm{mg}, \mathrm{Zn}-12.500,00 \mathrm{mg}$. e abatidas após jejum de 12 horas, por meio do corte da julgular. Em seguida, foram pesadas, sangradas, escaldadas, depenadas, evisceradas e pesadas novamente. As características de carcaça foram peso absoluto do frango ao abate (PA), peso da carcaça quente (frango eviscerado com cabeça e pés - CQ), peso da carcaça fria (frango eviscerado sem cabeça e sem pés - CF) e peso da carcaça após resfriamento de 24 horas (CRf).

A pesagem das vísceras comestíveis (moela, coração e fígado) foi realizada separadamente, logo após a limpeza de cada uma. Na moela, removeram-se toda a gordura aderida e seu conteúdo e cutícula internos (membrana coilina). Os cortes (peito, dorso, coxa, sobrecoxa e asa) foram feitos após 24 horas de resfriamento das carcaças dos frangos. $\mathrm{O}$ peso da gordura abdominal foi obtido pelo resultado do

Tabela 2 - Composição das rações experimentais fornecidas na fase de 8 a 21 dias de idade (\%Mn)

\begin{tabular}{|c|c|c|c|c|c|}
\hline \multirow[t]{3}{*}{ Item } & \multicolumn{5}{|c|}{ Ração (\%) } \\
\hline & \multirow[t]{2}{*}{ Referência } & \multicolumn{4}{|c|}{ Sorgo + Nível de OAA (\%) } \\
\hline & & 0,0 & 2,5 & 5,0 & 7,5 \\
\hline \multicolumn{6}{|l|}{ Ingrediente (\%) } \\
\hline Milho & 49,588 & - & - & - & - \\
\hline $\begin{array}{l}\text { Farelo de soja } \\
(45 \%)\end{array}$ & 12,764 & 15,379 & 25,418 & 34,785 & 36,254 \\
\hline $\begin{array}{l}\text { Soja integral } \\
\text { extrusada }\end{array}$ & 29,539 & 23,382 & 11,214 & - & - \\
\hline Sorgo & - & 57,048 & 56,729 & 55,854 & 48,442 \\
\hline $\begin{array}{l}\text { Óleo de abatedouro } \\
\text { avícola (OAA) }\end{array}$ & ro - & - & 2,500 & 5,000 & 7,500 \\
\hline Fosfato bicálcico & 1,783 & 1,746 & 1,750 & 1,755 & 1,776 \\
\hline Calcário & 1,068 & 1,082 & 1,062 & 1,043 & 1,026 \\
\hline Sal comum & 0,487 & 0,488 & 0,466 & 0,446 & 0,445 \\
\hline $\begin{array}{l}\text { Premix } \\
\text { vitamínico- } \text { mineral }^{1}\end{array}$ & 0,400 & 0,400 & 0,400 & 0,400 & 0,400 \\
\hline Inerte & 4,000 & - & - & 0,272 & 3,737 \\
\hline DL-met 99 & 0,223 & 0,250 & 0,253 & 0,255 & 0,261 \\
\hline L-Lys $\mathrm{HCl}$ & 0,148 & 0,225 & 0,208 & 0,190 & 0,159 \\
\hline \multicolumn{6}{|c|}{ Composição nutricional calculada } \\
\hline EM (kcal/kg) & 3.000 & 3.000 & 3.000 & 3.000 & 3.000 \\
\hline PB (\%) & 20,877 & 20,877 & 20,877 & 20,877 & 20,877 \\
\hline Met total (\%) & 0,544 & 0,563 & 0,566 & 0,568 & 0,572 \\
\hline $\begin{array}{l}\text { Met + Cys } \\
\text { totais (\%) }\end{array}$ & 0,879 & 0,879 & 0,879 & 0,879 & 0,879 \\
\hline Lisina total $(\%)$ & 1,239 & 1,239 & 1,239 & 1,239 & 1,239 \\
\hline Trip. total (\%) & 0,260 & 0,268 & 0,272 & 0,276 & 0,279 \\
\hline P disponível (\%) & 0,441 & 0,441 & 0,441 & 0,441 & 0,441 \\
\hline Сa $(\%)$ & 0,939 & 0,939 & 0,939 & 0,939 & 0,939 \\
\hline $\mathrm{Na}(\%)$ & 0,216 & 0,216 & 0,216 & 0,216 & 0,216 \\
\hline
\end{tabular}

1 Premix vitamínico e mineral para aves (ração crescimento): ácido fólico - 92,00 mg, ácido pantotênico - 2.230,00 mg, antifúngico - 5.000,00 mg antioxidante - 200,00 mg, biotina - 19,00 mg, Cu - 2.000,00 mg, coccidiostático $-15.000,00 \mathrm{mg}$, colina $-93.000,00, \mathrm{Fe}-12.500,00 \mathrm{mg}$, - 190,00 mg, Mn - 18.750,00 mg, menadiona - 460,00 mg, niacina - 6.975,00 $\mathrm{mg}$, piridoxina - $190 \mathrm{mg}$, vit. B12 - 3.330,00 mcg, vit. D3 - 460.000,00 UI vit. E - 3.725,00 mg, Zn - 12.500,00 mg. 
Tabela 3 - Composição das rações experimentais fornecidas na fase de 22 a 33 dias de idade (\%MN)

\begin{tabular}{|c|c|c|c|c|c|}
\hline \multirow[t]{3}{*}{ Item } & \multicolumn{5}{|c|}{ Ração (\%) } \\
\hline & \multirow[t]{2}{*}{ Referência } & \multicolumn{4}{|c|}{ Sorgo + Nível de OAA (\%) } \\
\hline & & 0,0 & 2,5 & 5,0 & 7,5 \\
\hline \multicolumn{6}{|l|}{ Ingrediente (\%) } \\
\hline Milho & 52,211 & - & - & - & - \\
\hline $\begin{array}{l}\text { Farelo de soja } \\
(45 \%)\end{array}$ & 6,818 & 9,047 & 19,086 & 29,124 & 32,706 \\
\hline $\begin{array}{l}\text { Soja integral } \\
\text { extrusada }\end{array}$ & 33,073 & 27,333 & 15,167 & 2,999 & - \\
\hline Sorgo & - & 59,633 & 59,313 & 58,994 & 53,399 \\
\hline $\begin{array}{l}\text { Óleo de abatedouro } \\
\text { avícola (OAA) }\end{array}$ & $0 \quad-$ & - & 2,500 & 5,000 & 7,500 \\
\hline Fosfato bicálcico & 1,645 & 1,608 & 1,611 & 1,615 & 1,632 \\
\hline Calcário & 1,034 & 1,048 & 1,029 & 1,010 & 0,992 \\
\hline Sal comum & 0,466 & 0,469 & 0,447 & 0,425 & 0,418 \\
\hline $\begin{array}{l}\text { Premix } \\
\text { vitamínico- } \\
\text { mineral }^{1}\end{array}$ & 0,400 & 0,400 & 0,400 & 0,400 & 0,400 \\
\hline Inerte & 4,000 & - & - & - & 2,612 \\
\hline DL-Met 99 & 0,199 & 0,228 & 0,230 & 0,233 & 0,238 \\
\hline L-Lys $\mathrm{HCl}$ & 0,154 & 0,234 & 0,217 & 0,200 & 0,173 \\
\hline \multicolumn{6}{|c|}{ Composição nutricional calculada } \\
\hline EM (kcal/kg) & 3.075 & 3.075 & 3.075 & 3.075 & 3.075 \\
\hline PB (\%) & 19,692 & 19,692 & 19,692 & 19,692 & 19,692 \\
\hline Met total $(\%)$ & 0,505 & 0,525 & 0,527 & 0,530 & 0,534 \\
\hline $\begin{array}{l}\text { Met + Cys } \\
\text { total (\%) }\end{array}$ & 0,827 & 0,827 & 0,827 & 0,827 & 0,827 \\
\hline Lisina total (\%) & 1,162 & 1,162 & 1,162 & 1,162 & 1,162 \\
\hline Trip. total (\%) & 0,241 & 0,249 & 0,253 & 0,257 & 0,261 \\
\hline P disponível (\%) & 0,412 & 0,412 & 0,412 & 0,412 & 0,412 \\
\hline $\mathrm{Ca}(\%)$ & 0,883 & 0,883 & 0,883 & 0,883 & 0,883 \\
\hline $\mathrm{Na}(\%)$ & 0,203 & 0,203 & 0,203 & 0,203 & 0,203 \\
\hline
\end{tabular}

1 Premix vitamínico e mineral para aves (ração crescimento): ácido fólico - 92,00 mg, ácido pantotênico - 2.230,00 mg, antifúngico - 5.000,00 mg, antioxidante - 200,00 mg, biotina - $19,00 \mathrm{mg}, \mathrm{Cu}-2.000,00 \mathrm{mg}$, coccidiostático - 15.000,00 mg, colina - 93.000,00, Fe - $12.500,00 \mathrm{mg}$ I - 190,00 mg, Mn - 18.750,00 mg, menadiona - 460,00 mg, niacina $6.975,00 \mathrm{mg}$, piridoxina - $190 \mathrm{mg}$, vit. B12 - 3.330,00 mcg, vit. D3 $460.000,00 \mathrm{UI}$, vit. E - 3.725,00 mg, Zn - 12.500,00 mg.

somatório da pesagem da gordura realizada em duas etapas: a primeira porção da gordura foi retirada da moela, logo após a evisceração das aves; e a segunda na região da cloaca, depois de 24 horas de resfriamento das carcaças.

Os rendimentos em porcentagem das carcaças quente $\mathrm{e}$ fria e os rendimentos das vísceras comestíveis e gordura abdominal (extraída da região da cloaca e da moela) foram calculados de acordo com o peso ao abate; os rendimentos das partes (peito, coxa, sobrecoxa, asa, dorso) foram obtidos em relação ao peso da carcaça após resfriamento de 24 horas.

A mensuração da intensidade da pigmentação das carcaças foi realizada pela medida da coloração da canela, das três aves, individualmente, de cada parcela experimental utilizando-se o Leque Colorimétrico Roche. Em seguida, foi determinada a média dos valores atribuídos para cada repetição.
Tabela 4 - Composição das rações experimentais fornecidas na fase de 34 a 42 dias de idade (\%MN)

\begin{tabular}{|c|c|c|c|c|c|}
\hline \multirow[t]{3}{*}{ Item } & \multicolumn{5}{|c|}{ Ração (\%) } \\
\hline & \multirow[t]{2}{*}{ Referência } & \multicolumn{4}{|c|}{ Sorgo + Nível de OAA (\%) } \\
\hline & & 0,0 & 2,5 & 5,0 & 7,5 \\
\hline \multicolumn{6}{|l|}{ Ingrediente (\%) } \\
\hline Milho & 64,035 & - & - & - & - \\
\hline $\begin{array}{l}\text { Farelo de soja } \\
(45 \%)\end{array}$ & 29,285 & 28,322 & 28,528 & 28,732 & 29,569 \\
\hline Óleo de soja & 3,000 & 5,000 & 3,000 & 1,000 & - \\
\hline Sorgo & - & 62,658 & 61,623 & 60,588 & 56,365 \\
\hline $\begin{array}{l}\text { Óleo de abatedouro } \\
\text { avícola (OAA }\end{array}$ & ro - & - & 2,500 & 5,000 & 7,500 \\
\hline Fosfato bicálcico & 1,433 & 1,415 & 1,418 & 1,421 & 1,433 \\
\hline Calcário & 1,003 & 1,007 & 1,004 & 1,002 & 0,992 \\
\hline Sal comum & 0,382 & 0,398 & 0,398 & 0,398 & 0,397 \\
\hline $\begin{array}{l}\text { Premix } \\
\text { vitamínico- } \\
\text { mineral }^{1}\end{array}$ & 0,400 & 0,400 & 0,400 & 0,400 & 0,400 \\
\hline Inerte & 0,149 & 0,381 & 0,715 & 1,048 & 2,947 \\
\hline DL-Met 99 & 0,168 & 0,211 & 0,211 & 0,212 & 0,216 \\
\hline L-Lys $\mathrm{HCl}$ & 0,145 & 0,208 & 0,203 & 0,199 & 0,181 \\
\hline \multicolumn{6}{|c|}{ Composição nutricional calculada } \\
\hline EM (kcal/kg) & 3.100 & 3.100 & 3.100 & 3.100 & 3.100 \\
\hline PB (\%) & 18,529 & 18,529 & 18,529 & 18,529 & 18,529 \\
\hline Met total $(\%)$ & 0,465 & 0,493 & 0,493 & 0,494 & 0,496 \\
\hline $\begin{array}{l}\text { Met }+ \text { Cys } \\
\text { total }(\%)\end{array}$ & 0,775 & 0,775 & 0,775 & 0,775 & 0,775 \\
\hline Lisina total $(\%)$ & 1,088 & 1,088 & 1,088 & 1,088 & 1,088 \\
\hline Trip. total (\%) & 0,229 & 0,240 & 0,241 & 0,241 & 0,243 \\
\hline P disponível (\%) & 0,327 & 0,327 & 0,327 & 0,327 & 0,327 \\
\hline Ca $(\%)$ & 0,828 & 0,828 & 0,828 & 0,828 & 0,828 \\
\hline $\mathrm{Na}(\%)$ & 0,192 & 0,192 & 0,192 & 0,192 & 0,192 \\
\hline
\end{tabular}

1 Premix vitamínico e mineral para aves (ração abate): ácido fólico $45,00 \mathrm{mg}$, ácido pantotênico - 1.080,00 mg, antifúngico - 5.000,00 mg antioxidante $-200,00 \mathrm{mg}$, biotina $-9,00 \mathrm{mg}, \mathrm{Cu}-2.000,00 \mathrm{mg}$, colina $64.000,00, \mathrm{Fe}-12.500,00 \mathrm{mg}, \mathrm{I}-190,00 \mathrm{mg}, \mathrm{Mn}-18.750,00 \mathrm{mg}$, menadiona - 230,00 mg, niacina - $3.380 \mathrm{mg}$, piridoxina - $90 \mathrm{mg}$, promotor de crescimento $-7.500,00 \mathrm{mg}$, riboflavina $-730,00 \mathrm{mg}$, Se $-75,00 \mathrm{mg}$ tiamina - $165,00 \mathrm{mg}$, vit. A $-900.000,00 \mathrm{UI}$, vit. B12 $-1.630,00 \mathrm{mcg}$ vit. D3 - 230.000,00 UI, vit. E - 1.800,00 UI, Zn - 12.500,00 mg.

As temperaturas médias máximas e mínimas foram, respectivamente, de 32 e $25^{\circ} \mathrm{C}$ e a umidade relativa do ar variou de 68 a $72 \%$.

Para a análise de variância dos dados, adotou-se o teste Student Newman Keuls, a 5\% de probabilidade para comparações dos tratamentos. As equações de regressão para a avaliação dos níveis de inclusão de óleo de abatedouro avícola foram ajustadas pelo programa estatístico SAS (1999) utilizando-se todas as variáveis, estabelecidas por modelo de regressão linear ou quadrático, conforme o melhor ajuste.

\section{Resultados e Discussão}

Não houve efeito de bloco sobre o desempenho das aves em todos os períodos experimentais (Tabela 5). O 
consumo diário de ração na fase pré inicial (1 a 7 dias) diferiu $(\mathrm{P}<0,05)$ entre os tratamentos e o pior resultado $(19,22 \mathrm{~g}$ de ração por ave) foi encontrado para o tratamento à base de sorgo sem utilização de OAA, que, no entanto, não diferiu do obtido com a ração à base de milho. Possivelmente, os níveis de aminoácidos do sorgo não atenderam às exigências nutricionais dos pintinhos nesta fase. Outros autores podem relatar que o sorgo na fase inicial pode influenciar negativamente pelo seu teor em tanino. Nas fases experimentais de 8 a 21 dias, 22 a 33 dias e 34 a 42 dias de idade, não houve diferença estatística para o consumo de ração.

Durante o período de 1 a 42 dias, o consumo de ração no tratamento à base de sorgo com $7,5 \%$ de OAA foi maior que no tratamento com sorgo sem inclusão de OAA. Entretanto, em trabalhos realizados por Dutra Jr. et al. (1991a), Lima et al. (1996), Pour-Reza \& Edriss (1997), o consumo alimentar não foi significativamente afetado pela adição de gordura animal ou óleo vegetal em dietas.

Na análise de regressão, excluindo-se o tratamento sem inclusão de OAA, durante os períodos de 1 a 7 dias, de 22 a 33 dias e de 1 a 42 dias de idade das aves, o consumo de ração aumentou linearmente com o aumento desse óleo na ração (Tabela 5), o que pode ser explicado pelo efeito benéfico das gorduras, pelo menor incremento calórico projetado na ração e pela palatabilidade e densidade da ração.

Andreotti et al. (2004) observaram resultados de consumo de ração semelhantes aos deste trabalho ao avaliarem o efeito da utilização do óleo de soja sobre o tempo de trânsito em rações isocalóricas, uma vez que houve aumento linear no consumo alimentar à medida que se elevou o nível de óleo na ração. No entanto, segundo Mateos \& Sell (1982), o consumo alimentar diminuiu em dietas acrescidas de gordura, uma vez que essas dietas provocam menor taxa de passagem do alimento.

No período de 1 a 7 dias, observou-se decréscimo $(\mathrm{P}<0,05)$ no ganho de peso das aves alimentadas com a ração à base de sorgo sem inclusão de OAA. De 8 a 21 dias, houve diferença significativa $(\mathrm{P}<0,05)$ entre as rações com $7,5 \%$ de OAA e à base de sorgo e as demais, de modo que a ração com sorgo e 7,5\% de OAA foi superior, com média de $67,46 \mathrm{~g}$.

O ganho de peso no período de 22 a 33 dias não diferiu significativamente entre as rações. Brue \& Latshaw (1985) encontraram em seus trabalhos, utilizando níveis que variaram de 2,5 a 10\% de diversas fontes de óleo, entre elas, o óleo de abatedouro avícola, comportamentos contrários,

Tabela 5 - Desempenho dos frangos de corte durante as fases experimentais

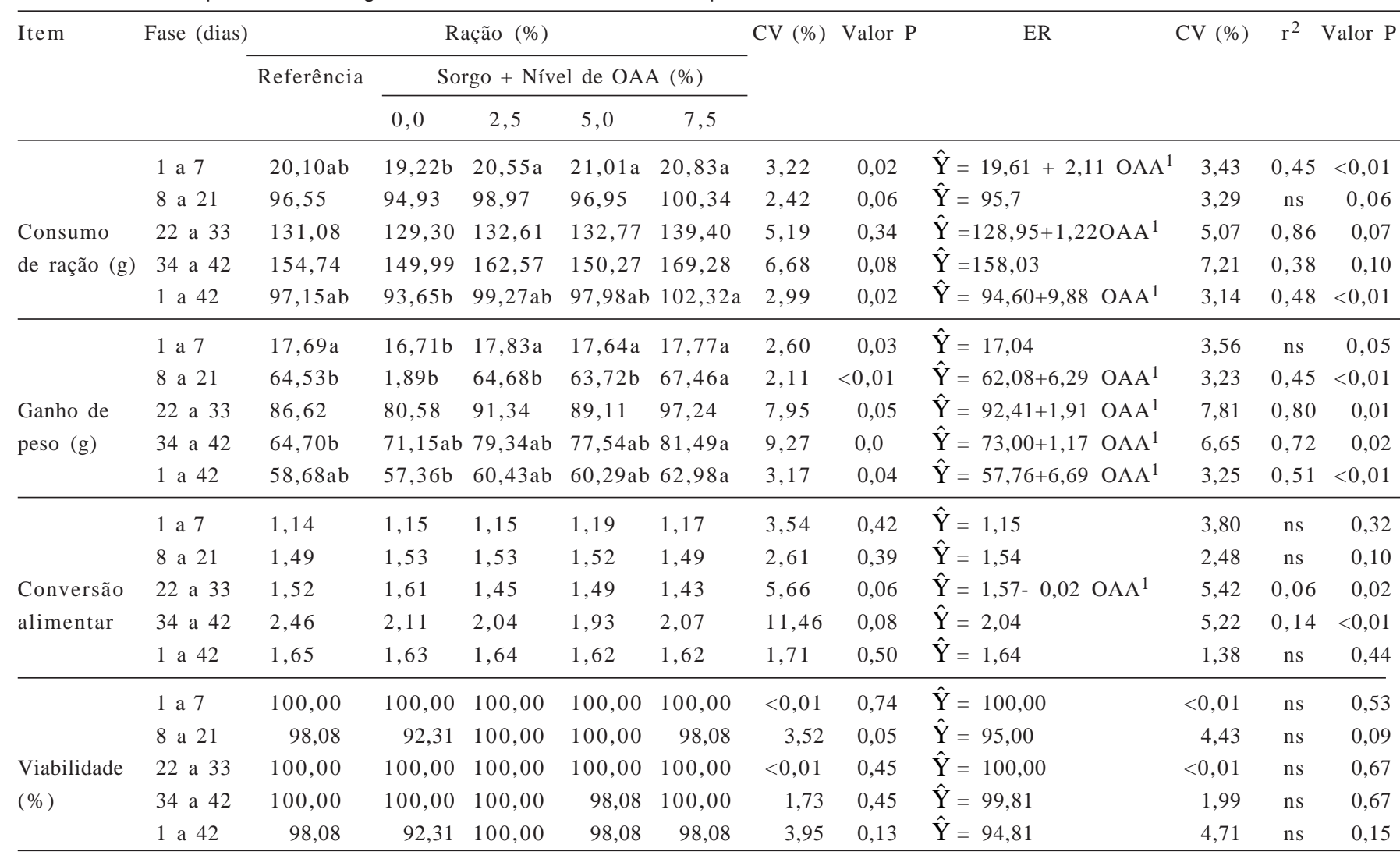


com aumento no ganho de peso dos frangos à medida que incluíram o óleo na ração.

No período de 34 a 42 dias, as aves alimentadas com ração à base de sorgo e 7,5\% de OAA obtiveram ganho de peso significativamente $(\mathrm{P}<0,05)$ melhor que o obtido com a ração-referência. Esses resultados divergem dos encontrados Pour-Reza \& Edriss (1997), que verificaram redução no peso vivo com dietas nas quais o sorgo substituiu $100 \%$ do milho.

Quando se verificou o ganho de peso durante toda fase experimental, de 1 a 42 dias de idade, o tratamento à base de sorgo sem a adição de óleo de abatedouro avícola foi estatisticamente inferior $(\mathrm{P}<0,05)$ àquele com maior inclusão de OAA, que apresentou média de 62,98 g de ganho diário por ave.

Douglas et al. (1988) e Reid (1985) verificaram que a adição de gordura animal na ração melhorou o valor nutricional do sorgo. Esse efeito positivo pode estar relacionado à gordura, que melhora a digestibilidade de componentes não lipídicos da dieta por reduzir a velocidade de passagem da digesta, ou à maior eficiência energética e ao menor incremento calórico, uma vantagem para animais em ambientes com temperaturas mais elevadas.

Observou-se resposta linear crescente das rações sobre o ganho de peso (Tabela 5) à medida em se aumentou o nível de OAA nas rações nas fases de 8 a 21 dias, 22 a 33 dias, 34 a 42 dias e de 1 a 42 dias. Esses dados estão de acordo com os encontrados por Dutra Jr. et al. (1991b), que também encontraram respostas positivas no ganho de peso das aves quando utilizaram níveis crescentes de 0, 2, 4, 6 e 8\% de óleo de abatedouro avícola nas rações.

Durante todos os períodos estudados, não houve diferença significativa entre as rações para a conversão alimentar. Comparando-se o efeito dos níveis de OAA na ração, verificou-se melhoria linear da conversão alimentar com o aumento da utilização do óleo no período de 22 a 33 dias de idade. Esses resultados podem ser explicados pela conversão alimentar, que está relacionada ao consumo de ração, que influencia diretamente o aumento do peso corporal, sugerindo que as aves apenas reagiram às alterações físicas e químicas das rações sem alterar a conversão alimentar.

Gualtieri \& Rapaccini (1990) também encontraram resultados semelhantes e afirmaram que dietas contendo sorgo de baixo tanino são equivalentes, em conversão alimentar, às dietas isoprotéicas à base de milho. De acordo com Dixit \& Baghel (1997), a conversão alimentar foi melhor em frangos alimentados com dietas com $100 \%$ de sorgo. Lima et al. (1996) também verificaram que o aumento nos níveis de inclusão de óleo melhorou significativamente a conversão alimentar.
A viabilidade em todas as fases experimentais não diferiu $(\mathrm{P}>0,05)$ entre as rações. Nos períodos de 1 a 7 dias e de 22 a 33 dias, não ocorreu nenhuma mortalidade dos frangos nos tratamentos.

Verificou-se efeito não-significativo $(\mathrm{P}>0,05)$ das rações sobre todos os parâmetros de desempenho estudados (Tabela 6). Avaliando-se o efeito dos níveis de inclusão do OAA nas dietas formuladas com sorgo, houve diferença significativa $(\mathrm{P}<0,05)$ apenas para o peso das aves ao abate, que elevou com o aumento dos níveis de óleo na ração.

O peso de carcaça quente apresentou maior valor numérico para as aves alimentadas com rações à base de sorgo com 7,5\% de inclusão de OAA, o que pode ser explicado principalmente porque também foi o tratamento que teve maior peso ao abate $(2.447,87 \mathrm{~g})$. Silva et al. (2003) mostraram claramente que o peso vivo do frango apresenta alta correlação com o peso de carcaça e dos cortes nobres.

Deaton et al. (1981) utilizaram três dietas com adição de 4,7 e 10\% de gordura animal e observaram que a deposição de gordura abdominal elevou com o aumento do nível de gordura na ração. Gaiotto et al. (2000) não observaram influência negativa de diversas fontes de gordura sobre o aumento da gordura abdominal.

Conforme a análise de regressão (Tabela 6), não houve efeito da adição de OAA sobre a pigmentação da carcaça quando comparados os tratamentos à base de sorgo com inclusões do óleo, uma vez que esta variável apresentou alto coeficiente de variação. Esses resultados podem ser atribuídos a características próprias da linhagem, que implica diferenças individuais na coloração das aves, ou ainda, a fatores metodológicos, como a pequena quantidade de aves amostradas para realização dessa avaliação e por esse parâmetro ser determinado subjetivamente, com a atribuição de valores julgados por um único observador. O método não é necessário para aves que praticamente não tinham pigmentação, ou seja, com baixa percepção.

Dutra Jr. et al. (1991b) observaram que a inclusão de óleo na ração melhorou a coloração da carcaça e atribuíram esta resposta favorável a um poder das gorduras e óleos em melhorar a absorção dos carotenóides, ou provavelmente a uma correção da relação energia : proteína.

Os rendimentos de carcaça, cortes nobres e vísceras comestíveis (Tabela 7) também não diferiram significativamente $(\mathrm{P}>0,05)$ segundo o teste SNK e a análise de regressão.

O peso absoluto e a porcentagem de gordura abdominal (Tabelas 6 e 7) apresentaram tendência de aumento com a inclusão de óleo na ração, mesmo não apresentando diferenças significativas. Sabe-se que o acúmulo de gordura na região abdominal em frangos de corte pode ser decorrente 
Tabela 6 - Peso do frango ao abate, peso das carcaças, peso dos cortes e das vísceras comestíveis, peso absoluto da gordura abdominal e valores da pigmentação da carcaça

\begin{tabular}{|c|c|c|c|c|c|c|c|c|c|c|c|}
\hline \multirow[t]{3}{*}{ Item } & \multicolumn{5}{|c|}{ Ração (\%) } & \multirow[t]{3}{*}{ CV (\%) } & \multirow[t]{3}{*}{ Valor P } & \multirow[t]{3}{*}{ ER } & \multirow[t]{3}{*}{ CV (\%) } & \multirow[t]{3}{*}{$r^{2}$} & \multirow[t]{3}{*}{ Valor P } \\
\hline & \multirow[t]{2}{*}{ Referência } & \multicolumn{4}{|c|}{ Sorgo + Nível de OAA (\%) } & & & & & & \\
\hline & & 0,0 & 2,5 & 5,0 & 7,5 & & & & & & \\
\hline PA & $2.336,61$ & 2306,49 & 2406,85 & 2413,40 & 2447,87 & 4,38 & 0,35 & $\begin{array}{l}\hat{\mathrm{Y}}=2329,05^{+} \\
1722,850 \mathrm{AA}\end{array}$ & 3,60 & NS & 0,04 \\
\hline $\mathrm{CQ}^{\mathrm{a}}$ & $1.887,72$ & $1.964,37$ & $2.039,10$ & $2.006,55$ & $2.113,00$ & 7,35 & 0,33 & $\hat{\mathrm{Y}}=1968,76$ & 4,98 & NS & 0,09 \\
\hline $\mathrm{CF}^{\mathrm{b}}$ & $1.816,83$ & $1.810,33$ & $1.884,04$ & $1.882,37$ & $1.913,87$ & 5,10 & 0,49 & $\hat{\mathrm{Y}}=1872,66$ & 4,30 & NS & 0,11 \\
\hline $\mathrm{CR}^{\mathrm{c}}$ & $1.998,20$ & $1.973,43$ & $2.046,98$ & $2.062,15$ & $2.094,70$ & - & - & . $\quad-$ & - & - & - \\
\hline Peito & 549,75 & 547,00 & 556,42 & 595,83 & 566,50 & 5,05 & 0,18 & $\hat{\mathrm{Y}}=551,75$ & 5,72 & NS & 0,20 \\
\hline Dorso & 344,29 & 327,79 & 345,33 & 329,71 & 353,75 & 7,41 & 0,57 & $\hat{\mathrm{Y}}=329,81$ & 6,21 & NS & 0,21 \\
\hline Coxa & 261,21 & 265,54 & 270,62 & 260,58 & 271,00 & 5,78 & 0,79 & $\hat{\mathrm{Y}}=265,99$ & 4,50 & NS & 0,82 \\
\hline Sobrecoxa & 306,83 & 310,54 & 325,46 & 315,17 & 327,12 & 7,20 & 0,63 & $\hat{\mathrm{Y}}=312,85$ & 5,90 & NS & 0,34 \\
\hline Asa & 193,67 & 191,92 & 195,58 & 196,83 & 198,08 & 5,25 & 0,91 & $\hat{\mathrm{Y}}=129,64$ & 4,26 & NS & 0,31 \\
\hline Fígado & 35,15 & 34,17 & 36,07 & 34,47 & 36,15 & 7,33 & 0,74 & $\hat{\mathrm{Y}}=34,57$ & 8,75 & NS & 0,54 \\
\hline Coração & 11,27 & 10,42 & 11,50 & 10,50 & 11,67 & 7,12 & 0,15 & $\hat{\mathrm{Y}}=10,61$ & 8,94 & NS & 0,23 \\
\hline Moela & 30,07 & 29,72 & 29,07 & 29,20 & 31,17 & 5,74 & 0,46 & $\hat{\mathrm{Y}}=29,12$ & 5,72 & NS & 0,26 \\
\hline Gordura abdominal & 48,42 & 49,14 & 56,04 & 60,61 & 64,10 & 29,34 & 0,60 & $\hat{\mathrm{Y}}=50,06$ & 20,66 & NS & 0,08 \\
\hline Pigmentação & 3,70 & 0,30 & 0,55 & 0,40 & 1,55 & 132,16 & 0,08 & $\hat{\mathrm{Y}}=0,16$ & 204,78 & NS & 0,28 \\
\hline
\end{tabular}

1 Ração-referência.

a Peso da carcaça quente: obtido do peso das aves após sangria, depenamento e evisceração.

b Peso da carcaça fria: determinado pelo peso da carcaça quente menos os pés e a cabeça das aves.

c Peso da carcaça resfriada: após 24 horas de resfriamento.

Tabela 7 - Rendimentos das carcaças, das vísceras comestíveis e da gordura abdominal em relação ao peso vivo antes do abate; e cortes, em relação ao peso da carcaça quente após 24 horas de resfriamento

\begin{tabular}{|c|c|c|c|c|c|c|c|c|c|c|}
\hline \multirow[t]{2}{*}{ Item } & \multicolumn{4}{|c|}{ Ração (\%) } & \multirow[t]{2}{*}{ CV (\%) } & \multirow[t]{2}{*}{ Valor P } & \multirow[t]{2}{*}{ ER } & \multirow[t]{2}{*}{ CV (\%) } & \multirow[t]{2}{*}{$r^{2}$} & \multirow[t]{2}{*}{ Valor $\mathrm{P}$} \\
\hline & Referência & 0,0 & 2,5 & 5,0 & & & & & & \\
\hline $\mathrm{CQ}^{\mathrm{a}}$ & 80,84 & 85,16 & 84,73 & 83,17 & 5,08 & 0,47 & $\hat{\mathrm{Y}}=0,85$ & 3,18 & ns & 0,78 \\
\hline $\mathrm{CF}^{\mathrm{b}}$ & 77,70 & 78,46 & 78,31 & 78,01 & 2,33 & 0,98 & $\hat{\mathrm{Y}}=0,78$ & 2,48 & ns & 0,79 \\
\hline Peito & 27,54 & 27,70 & 27,19 & 28,89 & 3,57 & 0,15 & $\hat{\mathrm{Y}}=0,28$ & 4,02 & ns & 0,88 \\
\hline Coxa & 13,06 & 13,45 & 13,22 & 12,64 & 4,06 & 0,34 & $\hat{\mathrm{Y}}=0,13$ & 3,75 & ns & 0,08 \\
\hline Sobrecoxa & 15,33 & 15,73 & 15,80 & 15,28 & 4,28 & 0,74 & $\hat{\mathrm{Y}}=0,16$ & 3,92 & ns & 0,54 \\
\hline Asa & 9,70 & 9,72 & 9,55 & 9,55 & 2,53 & 0,52 & $\hat{\mathrm{Y}}=0,10$ & 2,24 & ns & 0,12 \\
\hline Fígado & 1,50 & 1,48 & 1,50 & 1,43 & 5,48 & 0,70 & $\hat{\mathrm{Y}}=0,015$ & 7,19 & ns & 0,68 \\
\hline Coração & 0,48 & 0,45 & 0,48 & 0,43 & 5,27 & 0,09 & $\hat{\mathrm{Y}}=0,005$ & 7,18 & ns & 0,70 \\
\hline
\end{tabular}

${ }^{1}$ Ração-referência.

a Peso da carcaça quente, obtido do peso das aves após sangria, depenamento e evisceração.

b Peso da carcaça fria, determinado pelo peso da carcaça quente subtraído do peso de pés e cabeça das aves.

de fatores como sexo, densidade energética da dieta, temperatura ambiente, idade e origem da fonte lipídica da dieta, entre outros. Nesse caso, possivelmente, apesar de as dietas serem isoenergéticas, a eficiência de utilização da energia da dieta é correlacionada negativamente ao incremento calórico da dieta; assim, as dietas com os maiores níveis de OAA possuía menores incrementos calóricos e possibilitaram melhor eficiência de utilização de energia dietética.

De acordo com Lara et al. (2006), fontes lipídicas não influenciam o rendimento de carcaça, vísceras e cortes (peito e coxa) e a porcentagem de gordura abdominal.

Lima et al. (1996), observando o efeito do uso de óleo na ração de frangos de corte, verificaram que a inclusão de 
óleo de soja em níveis de 1, 2 e 3\% na ração não proporcionam diferenças significativas para as características de rendimento de carcaças, rendimento de coxa, rendimento de peito e rendimento de gordura abdominal. No entanto, Mendes et al. (2001) demonstraram que o aumento do nível de energia nas rações causa redução no rendimento de carcaça.

\section{Conclusões}

A utilização do sorgo em substituição total ao milho pode ser realizada a partir dos 8 dias de idade e não interfere negativamente nos dados de desempenho e rendimento de carcaça. A adição de até 7,5\% de OAA em rações à base de sorgo possibilita a produção de carcaças com rendimentos semelhantes ao daquelas alimentadas com rações à base de milho e farelo de soja, no entanto, não proporciona aumento significativo da coloração da carcaça, que depende do uso de pigmentos na ração.

\section{Literatura Citada}

ANDREOTTI, M.O.; JUNQUEIRA, O.M.; BARBOSA, M.J.B. et al. Efeito da adição do óleo de soja sobre a composição corporal em frangos de corte. Revista Brasileira de Ciência Avícolas, v.2, suplemento 2, p.17-17, 2000.

ANDREOTTI, M.O.; JUNQUEIRA, O.M.; BARBOSA, M.J.B. et al. Tempo de trânsito intestinal, desempenho, características de carcaça e composição corporal de frangos de corte alimentados com rações isoenergéticas formuladas com diferentes níveis de óleo. Revista Brasileira de Zootecnia, v.33, n.4, p.870-879, 2004.

ANUALPEC. Anuário da Pecuária Brasileira. São Paulo: Argos, 2000. p.265-292.

ARELLANO, D.B. Utilização de óleos e gorduras em rações avícolas: características dos produtos disponíveis no mercado. . In: CONFRÊNCIA APINCO DE CIÊNCIAS E TECNOLOGIA AVÍCOLAS, 1992, Santos. Anais... Santos: Fundação APINCO de Ciência e Tecnologia Avícolas, 1992. p.21-27.

BELL, D.E.; MILES, R.D. The influence of different cereal grains on broiler performance carcass composition and quality. Poultry Science, v.64, p.2119-2130, 1985.

BRUE, R.N.; LARSHAW, J.D. Energy utilization by the broiler chicken as affected by various fats and fat levels. Poultry Science, v.64, p.2119-2130,1985.

CHIU, M.C.; GIOIELLI, L.A. Propriedades físico-químicas das misturas de gordura abdominal de frango, suas estearinas e gordura de toucinho. Revista Brasileira de Ciência Farmacêutica, v.36, p.41, 2000 (supl. 1).

DEATON, J.W.; MCNAUGHTON, J.C.; REECHO, F.N. et al. Abdominal fat of broilers as influenced by dietary level of animal fat. Poultry Science, v.60, p.1250-1253, 1981.

DIXIT, R.; BAGHEL, R.P.S. Effect of feeding sorghum instead of maize on the performance of broilers. Indian Journal Animal Nutrition, v.14, p.272-274, 1997.

DOUGLAS, J.H.; SULLIVAN, T.W.; BOND, P.L. et al. Use of animal fat to correct the lower ME and nutritional value of high tannin grain sorghum. Poultry Science, v.67, p.80, 1988.

DUTRA JR., W.M.; ARIKI, J.; KRONKA, S.N. et al. Óleo de abatedouro avícola em comparação ao óleo de soja na alimentação de frangos de corte. Revista da Sociedade Brasileira de Zootecnia, v.20, n.5, p.471-475, 1991a.

DUTRA JR., W.M.; ARIKI, J.; KRONKA, S.N. et al. Níveis de óleo de abatedouro avícola no desempenho e características da carcaça de frangos de corte. Revista da Sociedade Brasileira de Zootecnia, v.20, n.5, p.475-482, 1991b.

GAIOTTO, J.B.; MENTEN, J.F.; RACANICCI, A.M.C. et al. Óleo de soja, óleo ácido de soja e sebo bovino como fontes de gordura em rações de frangos de corte. Revista Brasileira de Ciência Avícola, v.2, n.3, p.219-228, 2000.

GUALTIERI, M.; RAPACCINI, S. Sorghum grain in poultry feeding. World's Poultry Science Journal, v.46, p.246-254, 1990.

LARA, L.J.C.; BAIÃO, N.C.; AGUILAR, C.A.L. et al. Rendimento composição e teor de ácidos graxos da carcaça de frangos de corte alimentados com diferentes fontes lipídicas. Arquivo Brasileiro de Medicina Veterinária e Zootecnia, v.58, n.1. 2006.

LIMA, C.A.R.; SALLES, G.S.; CURVELLO, F.A. Efeito do uso de óleo em rações de frangos de corte criados no verão. In: CONFRÊNCIA APINCO DE CIÊNCIAS E TECNOLOGIA AVÍCOLAS, 1996, Curitiba. Anais... Curitiba: Fundação APINCO de Ciência e Tecnologia Avícolas, 1996. p.5.

MARUSICH, W.L.; BAUERFEIND, J.C. Oxycarotenoids in poultry feeds in carotenoids as colorants and vitamin $A$ precursors. New York: Academic Press, 1981. p.319

MATEOS, G.G.; SELL, J.L. Rate of food passage (time transit) as influenced by level of supplemental fat. Poultry Science, v.61, p.94-100, 1982.

NYACHOTI, C.M.; ATKISON, J.L.; LEESON, S. Response of broiler chicks fed a high tannin sorghum diet. Journal of Applied Poultry Research, v.5, p.239-245, 1996.

POUR-REZA, J.; EDRISS, M.A. Effects of dietary sorghum of different tannin concentrations and tallow suplementation on the performance of broiler chicks. British Poultry Science, v.38, p.512-517, 1997.

RACANICCI, A.M.C.; MENTEN, J.F.M.; D’ARCI, M.R. Oxidação lipídica reduz o conteúdo de energia metabolizável do óleo de víceras de aves para frangos de corte na fase de crescimento. In:REUNIÃO ANUAL DA SOCIEDADE BRASILEIRA DE ZOOTECNIA, 2002, Recife. Anais... Recife: Sociedade Brasileira de Zootecnia, 2002. (CD-ROM).

REID, B.I. Calorific value of fat. In: CORNELL NUTRITION CONFERENCE FOR FEED MANUFACTURES, 1985, Ithaca. Proceedings... Ithaca: Cornell University, 1985. p.5-9.

ROSTAGNO, H.S.; ALBINO, L.F.T.; DONZELE, J.L. et al. Composição de alimentos e exigências nutricionais de aves e suínos: tabelas brasileiras. Viçosa, MG: Universidade Federal de Viçosa, 2000. 141p.

SILVA, J.H.V.; ALBINO, L.F.T.; NASCIMENTO, A.H. Estimativas da composição anatômica da carcaça de frangos de corte com base no nível de proteína na ração e peso da carcaça. Revista Brasileira de Zootecnia, v.32, n.2, p.344-352, 2003.

STATISTICAL ANALYSIS SYSTEM - SAS. User's guide: statistics. Cary: 1999. (CD-ROM).

TABOSA, J.N.; FRANÇA, J.G.E.; SANTOS, J.P.O. et al. Teste em linhas de sorgo no semi-árido de Pernambuco para consumo humano. Pesquisa Agropecuária Brasileira, v.28, n.12 p.1385-1390, 1993.

VASCONCELOS, A.P. Utilização do urucu (Bixa orellana) como pigmentante em rações para frangos de corte à base de sorgo. Recife: Universidade Federal Rural de Pernambuco, 1988. 62p. Dissertação (Mestrado em Zootecnia) - Universidade Federal Rural de Pernambuco, 1988.

WHITAKER, H.M.A.; CARVALHO, R.L. Substituição do milho pelo sorgo em rações para eqüinos. Revista Brasileira de Zootecnia, v.26, n.1, p.139-143,1997.

ZARDO, A.O.; LIMA, G.J.M.M. Alimentos para suínos. Concórdia: Embrapa Suínos e Aves, 1999. 71p. (Boletim Informativo de Pesquisa). 